\title{
LOOKING FOR THE OPTIMAL LOCATION FOR WIND FARMS
}

\author{
Jerzy Montusiewicz' ${ }^{1}$ Michalina Gryniewicz-Jaworska', Paweł Pijarski² \\ 1 Institute of Computer Science, Lublin University of Technology, Nadbystrzycka 36b, 20-618 Lublin, Poland, \\ e-mail: j.montusiewicz@pollub.pl \\ 2 Chair of Electrical Networks and Security, Lublin University of Technology, Nadbystrzycka 38d, 20-618 Lublin, \\ Poland
}

Received: 2015.07.15

Accepted: 2015.08.05

Published: 2015.09.01

\begin{abstract}
Currently, wind power is a leader in the renewable energy sector. One of the many advantages of the development of renewable energy sources is small harm to the environment. Nevertheless, in order to install a wind farm we must overcome a number of obstacles associated with it. One of the many stages of the construction of wind turbines is designing its proper location. It is a very complex process, in which a number of criteria must be analysed, often hardly comparable with each other and even contradictory. The paper presents the concept of selecting a wind farm location using multicriteria optimisation methods.
\end{abstract}

Keywords: wind farm localisation, multicriteria optimisation methods.

\section{INTRODUCTION}

One of the many reasons for interest in wind farms is the systematic use of traditional energy resources, such as natural gas, oil or coal. Furthermore, the increase of carbon dioxide emissions into the atmosphere encourages us to seek alternative energy supplies [4, 9]. Issues related to the use of renewable energy sources are currently the subject of many scientific studies, both in Europe and worldwide [15, 19].

One of the sources of renewable energy is wind power, whose share is growing quite rapidly. Nevertheless, it is accompanied by a lot of barriers, which can include: legal, social, financial and technical aspects, the latter including geographical location and accessibility to the energy network. Despite the many problems that need to be addressed in the design and installation of wind farms, their number is constantly growing $[18,21]$.

\section{WIND ENERGY DEVELOPMENT}

The use of wind as an energy resource is an alternative to traditional methods of generating energy because it does not emit any pollutants. At wind speeds greater than $5 \mathrm{~m} / \mathrm{s}$ the unit price of energy obtained from wind power is more economical than the price of electricity from conventional thermal power plants. The constantly growing development of wind energy entails a decrease in energy costs and encourages investors to construct and install wind farms. However, to build a wind turbine requires certain specific wind conditions in the area so that they are optimal and generate profits rather than losses. Analysing the wind energy market in other European countries and in the world, Poland has a rather weak performance in the rankings. This is due to the natural conditions of the country, which lacks sufficient exposure to strong winds. Currently in Poland large wind farms are built in locations identified as beneficial, given the prevailing wind conditions, so that expenditures generate profits. Figure 1 presents a summary regarding the participation of wind generation in the electricity consumption in 2004-2010 in Poland $[6,7]$ and a comparison with selected European countries. Currently, the number of installations of wind farms is growing steadily.

The wind energy sector is developing in two main directions, i.e. land wind power (onshore 
a)

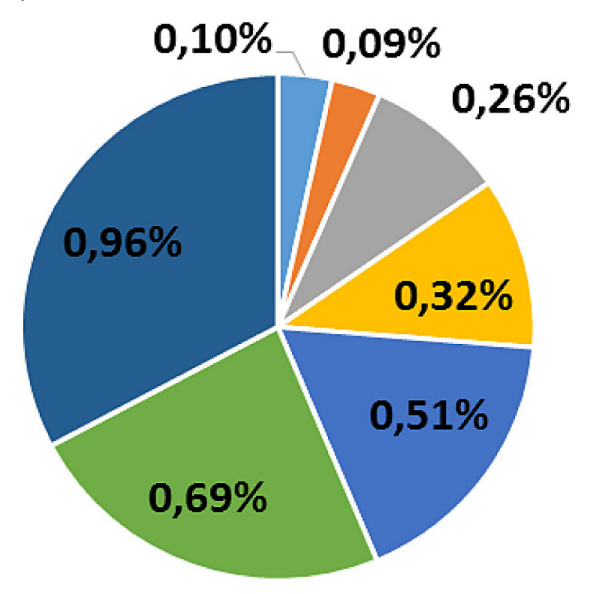

b)

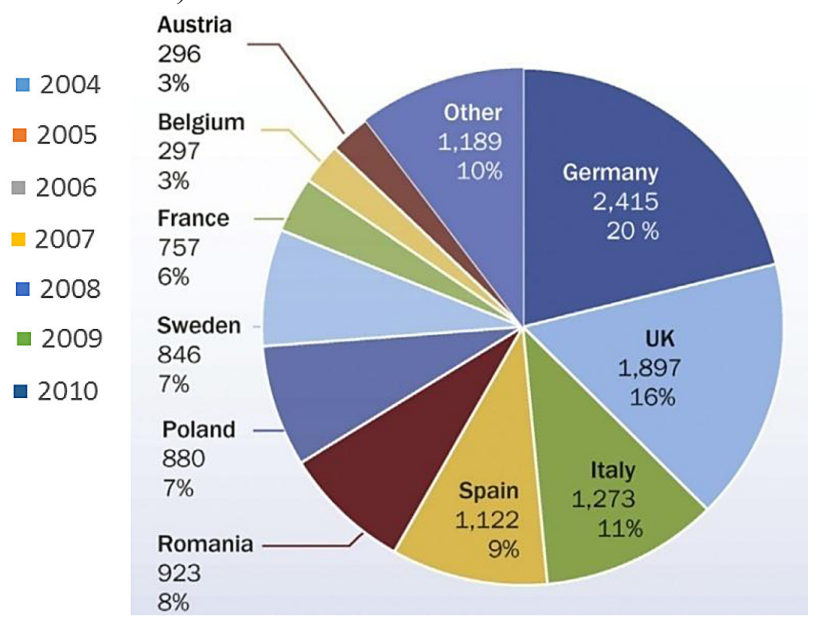

Fig. 1. Market share in wind power capacity: a) in Poland during 2004-2010 [14, 21]; b) in EU member states during 2012 (in MW) [20]

wind power), and sea wind power (offshore wind power). Land wind power stations comprise several different solutions:

- large-scale wind power generation, which includes a single turbine with a typical capacity of more than $1 \mathrm{MW}$ and wind farms consisting of several dozen wind turbines that generate electricity in order to sell it to the network,

- distributed wind power (small and distributed wind energy), which consists of single wind turbines with a capacity not exceeding $100 \mathrm{~kW}$, located mainly in the vicinity of farms as an alternative energy source,

- medium scale wind energy, which can include a single turbine with a capacity in the range of $200-600 \mathrm{~kW}$, connected to the grid, owned by individual customers, small businesses and the local community.

An important direction is the development of offshore wind energy, with the wind farms located out at sea. Currently, there are wind turbines with a horizontal axis of the rotor and three blades, and towers to the height of 100 meters. Wind farms can harness the power of up to $30 \%$; in the case of offshore wind farms the efficiency ranges from $40 \%$ to $50 \%$.

Standard wind turbines start working with the wind speed of $3 \mathrm{~m} / \mathrm{s}$ and achieve nominal power at about $12 \mathrm{~m} / \mathrm{s}$ [4]. Currently, we can distinguish many different types of wind turbines, which can include: reel, carousel, Darrieus, Beoning MOD2 and rotor Savonius [14, 21].

According to a studyin Poland, almost $40 \%$ of the country can be used for wind energy, tak- ing into account the criterion of profitability in $1000 \mathrm{kWh} / \mathrm{m}^{2} /$ year at the height of 30 minroughnessclass "0", assuming that the wind speed is about $4 \mathrm{~m} / \mathrm{s}$. According to the observational data of the Institute of Meteorology and Water Management, the most favourable conditions in terms of wind energy resources are to be found in the areas below:

- Baltic Sea coast, and in particular its central stretch, Koszalin area, northern part of the Hel peninsula and the island of Uznam,

- Greater Poland and Masovia,

- The Silesian and Żywiec Beskid Mountains,

- The Dynów Foothills and the Bieszczady Mountains.

Figure 2 presents (in blue) the capacity installed with the number of wind turbines by 2012 $[6,7]$.

The wind speed and direction at a given point consists of a number of factors which can include: terrain, air temperature, the local atmosphere equilibrium, the type of land cover (roughness), the presence of bodies of water, all kinds of buildings, large trees, etc.

Wind speed is constantly changing: it is different in the summer and in the winter. Even during the day it varies: the biggest wind speeds are recorded in the afternoon. It may result from turbulence and vertical exchange of momentum, which decreases in the evening. It may also be noted that the greatest wind speeds occur in the winter months. Analysing the wind conditions for the installation of wind farms we should consider the average wind speed at a certain use exporters 


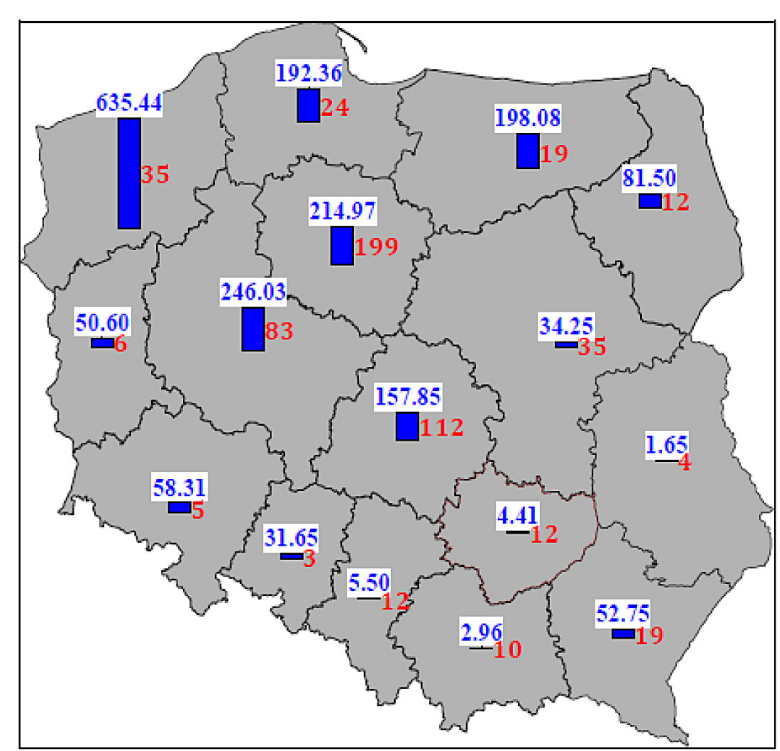

Fig. 2. Installed capacity (in blue) with the number of wind turbines by $2012[3,6]$

and the distribution of wind speed over time. Figure 3 presents the course of the wind flow through a classical wind turbine, the type most often used in wind farm construction in Poland.

The power output of the wind power generated in the engine obtained from the air flow seen from the air kinetic difference before and behind the rotor. Expression (1) contains the formula for the power carried by the wind passing through a circular surface defined by the rotation of the rotor.

$$
P_{u}=\rho \cdot \frac{\pi \cdot r^{2}}{2} \cdot v_{s} \cdot \frac{v_{o}^{2}-v_{k}^{2}}{2}
$$

Formula (1) describes the power carried by the wind passing through the circular surface of the rotor rotation specified where $[3,12]$ :

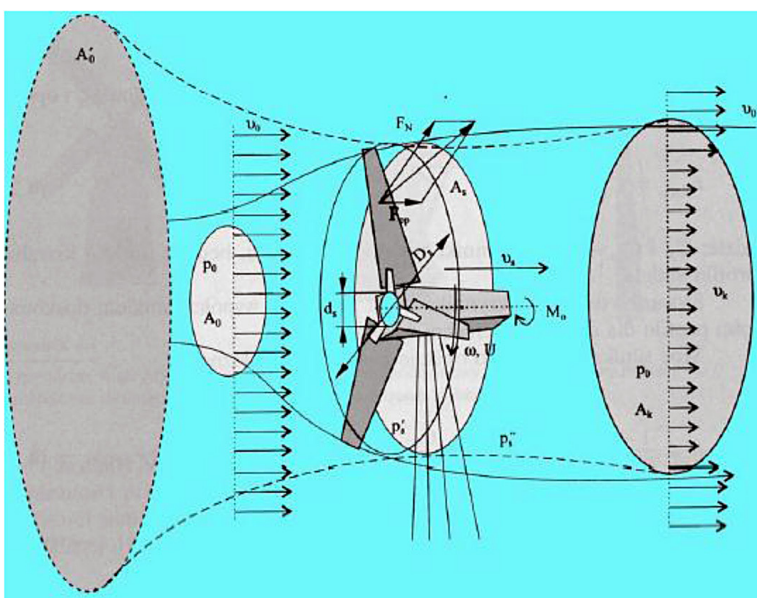

Fig. 3. Flow diagram of the wind through the wind turbine $[3,14]$
$P_{u}$ - wind power output [W],

$\rho$ - air density $\left[\mathrm{kg} \cdot \mathrm{m}^{-3}\right]$,

$v_{s}$ - the average speed of air flowing through the rotor $\left[\mathrm{m} \cdot \mathrm{s}^{-1}\right]$,

$v_{o}$ - wind speed upstream of the rotor $\left[\mathrm{m} \cdot \mathrm{s}^{-1}\right]$,

$v_{k}$ - wind speed for the rotor $\left[\mathrm{m} \cdot \mathrm{s}^{-1}\right]$,

$r$ - the radius of the rotor [m].

\section{THE CONCEPT OF SELECTING THE WIND FARM LOCATION}

The process of designing and establishing a wind farm location is a multi-stage activity. In [15] the authors propose an approach which distinguishes several steps, as shown by Figure 4 .

To determine the optimal location, the authors [15] use GIS system tools and the ELECTRE TRI method. On the basis of the collected field data, determining a set of restrictions imposed on them, e.g. the deployment of existing farms or the location of urban areas, and defining and adopting a set of criteria considered, the authors arrived at a base of potential farm locations.

The GIS is a computer system used for capturing, storing, checking, integrating, manipulating, analysing and displaying data related to positions on the Earth's surface. It is used to manipulate multiple objects associated with map databases. GIS functions allow to represent several different layers, each layer having data on a particular type of function. Each feature is associated with the location of the graphic image of the map. Details concerning the action phases carried out by the GIS method were described by those authors in article [16], Figure 5.

Used by $[15,16]$, the ELECTRE TRI method allows for the classification of decision variants to predefined ones and of orders from best to worst (descending) and from worst to best (ascending). The result of the obtained rankings depends on the adopted parameters of the calculation process. The assigned variances reflect in some way the categories of solutions defined as obtained by the process from a pessimistic or optimistic point of view. Due to the increase in interest in wind power and installation of wind farms, many professionals constantly strive to use the best methods that will allow them to select the best locations for the construction and installation of wind farms.

The essence of this approach is the separation of the stage of generating a database of available farm localization from the stage of selecting the 


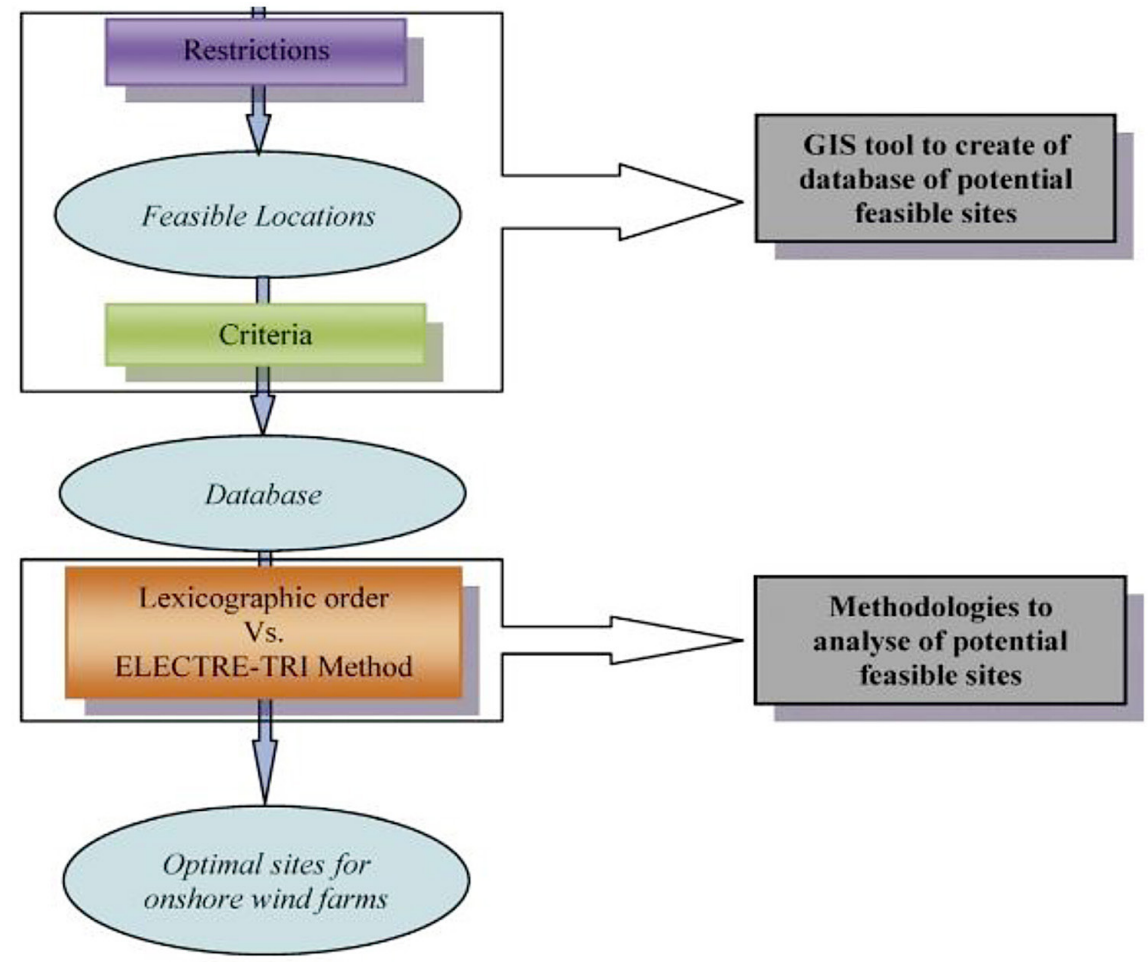

Fig. 4. Action scheme used in establishing the location of wind farms in the region of Murcia in Spain [15]

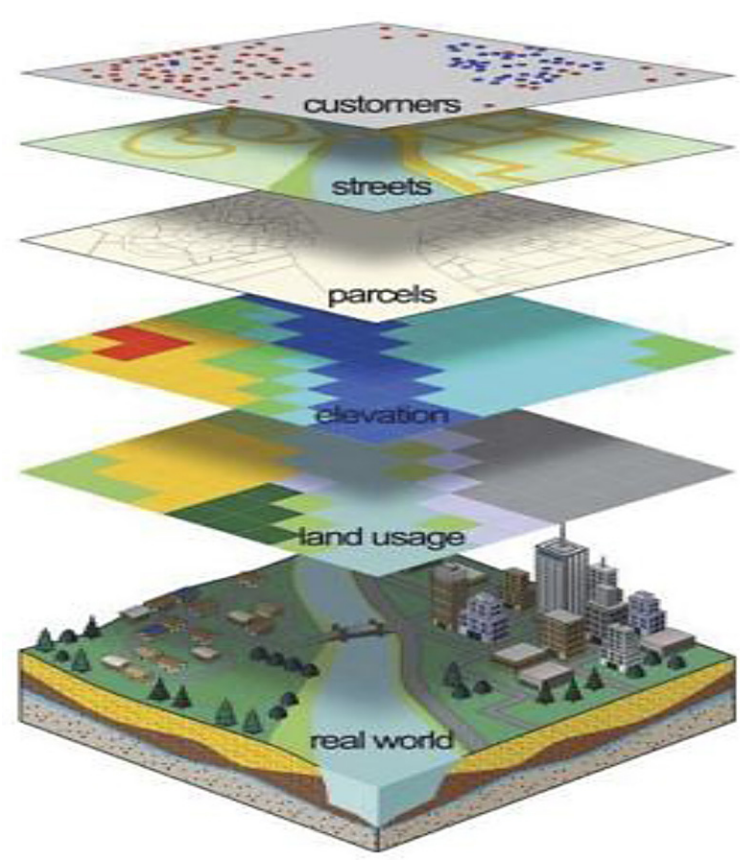

Fig. 5. Example of GIS layers [16]

optimal solutions by using one of the available methods of multi-criteria optimisation - ELECTRE TRI. The authors of the present study propose their own approach, illustrated in Figure 6.

From the literature data it appears that there are certain restrictions that must be met. After reducing the restrictions by using GIS tools a graphical representation is created of possible lo- cations for wind farms. The next step is to define a series of criteria that must be met and the analysis of those criteria must be maximised (or minimised) are determined group of non-dominated solutions. Using the methods of multicriteria optimisation we arrive at a specific group of feasible solutions that allow to identify a set of optimal locations of wind farms.

At the design stage, wind farms should consider a number of different factors. Some of them may be treated as limitations, and some as optimisation criteria. The difference between them is that limitations have to be met, while criteria are optimised. Depending on what they describe, we try for them to achieve the lowest or the highest possible value. In [15] the authors distinguish 4 different categories of criteria: environment, orography, location and climatology. It seems that at an early phase of determining a wind farm's localisation one should first of all precisely define the limitations set, which will be significantly reduced by available localisations. The most important limitations that should be considered include hardly comparable and even contradictory criteria. Therefore, determining the location of the construction phase and the placement of wind turbines is a very difficult and complicated process, requiring extensive knowledge of various fields of engineering. The most important criteria to be 


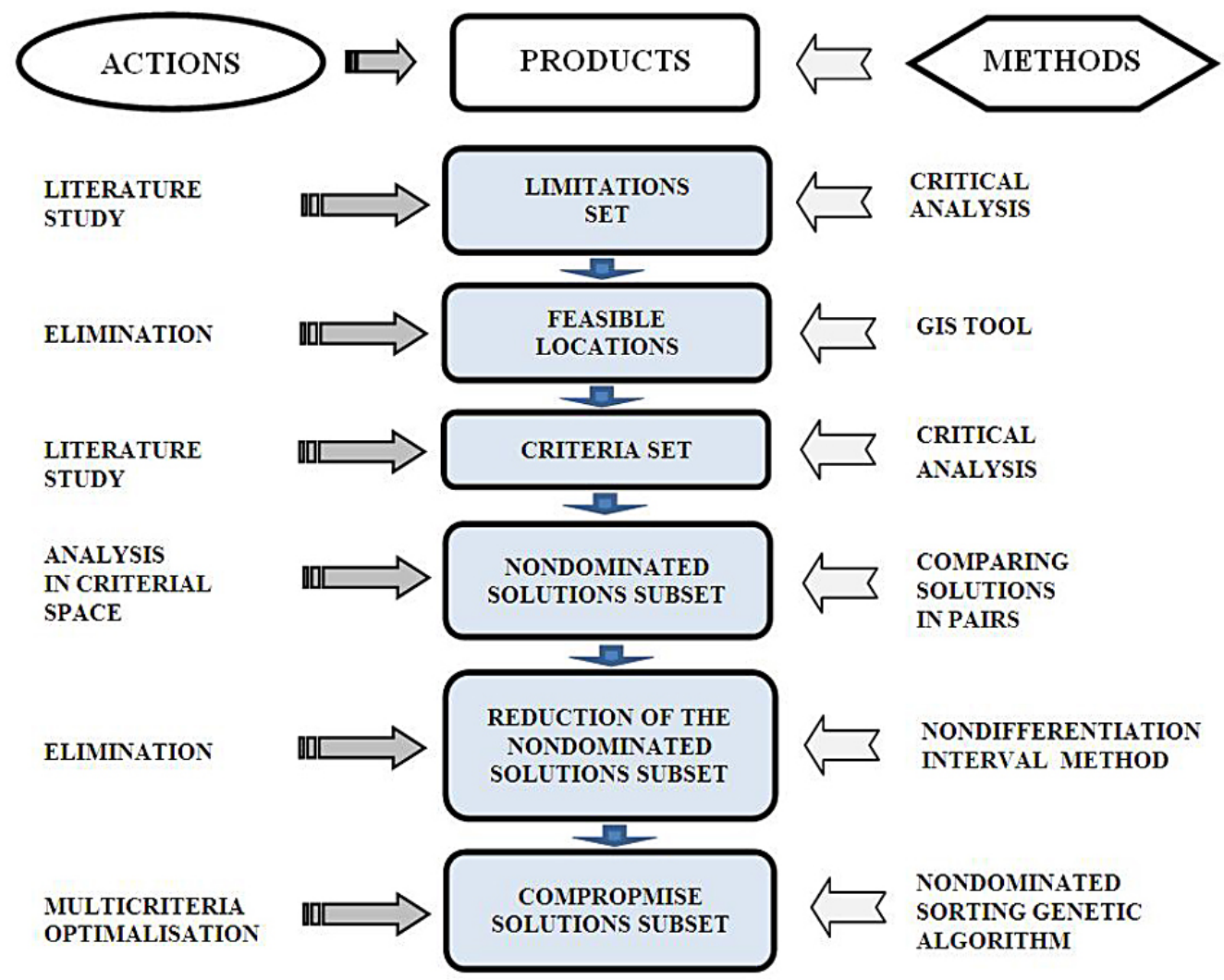

Fig. 6. Proposed action scheme in establishing the location of wind farms

specified are: wind speed, roughness of the terrain, type of land, flickering lights (between the blades of a windmill), noise produced by wind installations, impact on the environment, distance from residential areas, tourist attractiveness, price of land or land lease.

In articles $[15,16]$ the authors take into account additional criteria, such as distance to power lines, land inclination, distance to main airports and distance to electricity transformer substations. It should be noted, however, that all the criteria are expressed in different units, such as wind speed in $\mathrm{m} / \mathrm{s}$, the roughness of the terrain in classes, the price of land, the minimum distance from builtup areas in meters. Other criteria are in different units, moreover, it must be added that some of the criteria we will want to maximise and minimise. We will maximise the wind speed or the distance from residential areas, while minimising the criteria related to noise, flicker effect, the price of the land or the impact on the environment.

At the design stage wind farms should consider a number of criteria, which is difficult with most of them being hardly comparable. Currently, to solve complex optimisation tasks we use evolutionary algorithms that allow to obtain satisfactory results.

\section{MULTIOBJECTIVE EVOLUTIONARY ALGORITHMS}

The adopted set of criteria allows one to build a task of multi-criteria optimization wind farm the location. Generally, the decision maker should seek to reduce the number of criteria, because then the task becomes easier to calculate and interpret, especially when the number of criteria is 3 or 2 . The number of criteria can be reduced in three ways: moving some of the criteria to the set of restrictions and giving them values satisfying the decision-maker, aggregation of selected criteria in to one criterion (criteria expressed in the same units) and by removing from a set of (criteria corresponding to another criterion).

The use of multicriteria optimisation to find the optimal solution is not as simple as in the case when we consider one of the criteria and are looking for the largest or smallest value of the objective function $[1,2]$. The aim of multicriteria optimisation is to find the optimal solution, which is acceptable from the point of view of each criterion $[5,8,17]$. Today, for solving multicriteria optimisation evolutionary algorithms are commonly used. The principle of operation of an evolutionary algorithm consists in treating the population 
of individuals, each of which is a proposal to solve a specific problem. All individuals are assigned a value, called adaptation of the subject; moreover, they are equipped with a genotype, based on the created phenotype. The principle of the algorithm is then to repeat the loops, which follow each other: reproduction (genetic operations), evaluation and succession [10].

One of the evolutionary algorithms which can be used for the design of wind farms is the Nondominated Sorting Genetic Algorithm (NSGA). It uses Goldberg's method from 1989 and focuses on the distribution of individuals eligible (those that satisfy all the constraints imposed in formulating tasks) in subpopulations, taking into account the rank assigned to each analysed solution. The method can be used to solve problems with multiple criteria, in both cases minimising and maximising the criterion function. Next, using the method of measuring the niche guarantees to cover a set of solutions. The NSGA algorithm, Figure 7, by giving the same value to creating a subset of individuals to adapt non-dominated solutions, provides the same reproductive potential of many different individuals [13].

\section{The steps of the NSGA algorithm:}

1) With a population of feasible solutions $P_{G}$, all individuals that are not dominated eligible for the first subset (Front 1).

2) Individuals form a subset which receives the same amount of artificial adaptation (Front 1 will be set to 1 ).

3) The group of nondominated individuals (forming Front 1) is temporarily eliminated from the set of feasible solutions.

4) The remaining population is subjected to the same mechanism as in points 1-3 to form successive subsets (Front 2, 3, etc.). The broadcast of artificial adaptation is as follows: for Front $2-1 / 2$, for Front $3-1 / 3$, etc.

5) The end of the division after the classification of the whole population of feasible solutions.

6) After the sorting of the entire population of feasible solutions is carried out, operations of selection, crossover and mutation take place and create a new population of $P_{G}$ (where $\mathrm{G}=\mathrm{G}+1)$.

The share of individuals in this process depends on the value of the adaptation.
The NSGA algorithm presented above can be used in the design of wind farm location. Given the many criteria that we need to consider, and the fact that several of these criteria you will want to minimise and maximise, an attempt to implement the above evolutionary algorithm will provide a set of optimal solutions.

In the case of the NSGA method the selection of optimal solutions was made in the set of feasible solutions, i.e. those that met all the restrictions introduced. Choosing the best wind farm location in the area may also be implemented by a search in the set of nondominated solutions. Such solutions, of course, meet all of the restrictions introduced, but none of them is able to exclude the others. In the mathematical sense such solutions are thus equal, and to separate them new computational mechanisms and sorting conceptions must be used. One such proposal is optimality in the sense of the nondifferentiation interval, described by Montusiewicz [11, 12]. This approach does not use Euclidean metric, but introduces decomposition of the neighbourhood to neighbourhoods considered in terms of the individual criteria. Assessments of these neighbourhoods are, however, dealt with simultaneously and interlinked, which means that we are still dealing with a multicriteria task (Fig. 8).

Solution assessments $\mathrm{F}\left(\mathrm{x}^{+}\right)$and $\mathrm{F}\left(\mathrm{x}^{\wedge}\right)$ are nondominated, because solution $\mathrm{x}^{\wedge}$ has a lower value of criterion $F_{1}$ and a higher value of criterion $\mathrm{F}_{2}$ than solution $\mathrm{x}+$. The method introduces a modified mutation, which "worsens" virtually, by an amount calculated from the accepted nondifferentiation interval $P N$, the components of the criteria which had lower values for the solution

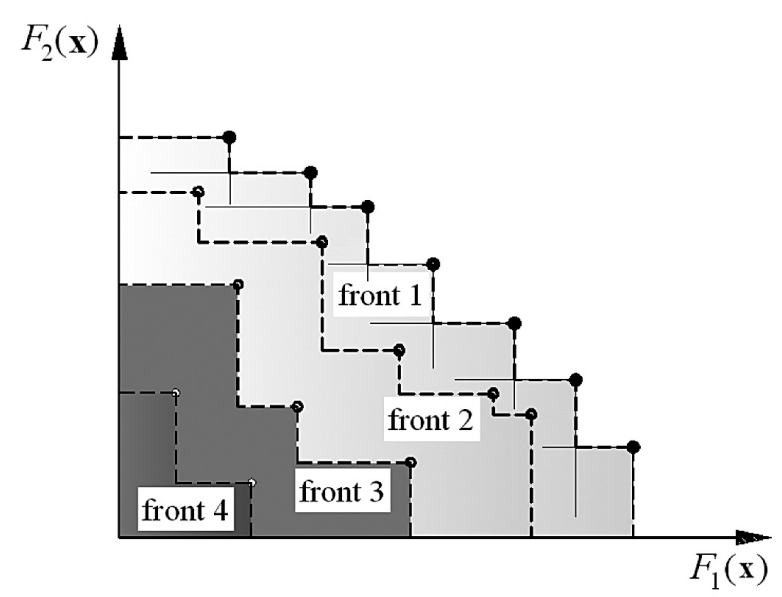

Fig. 7. Selection in NSGA algorithm for the case of maximising both criteria 


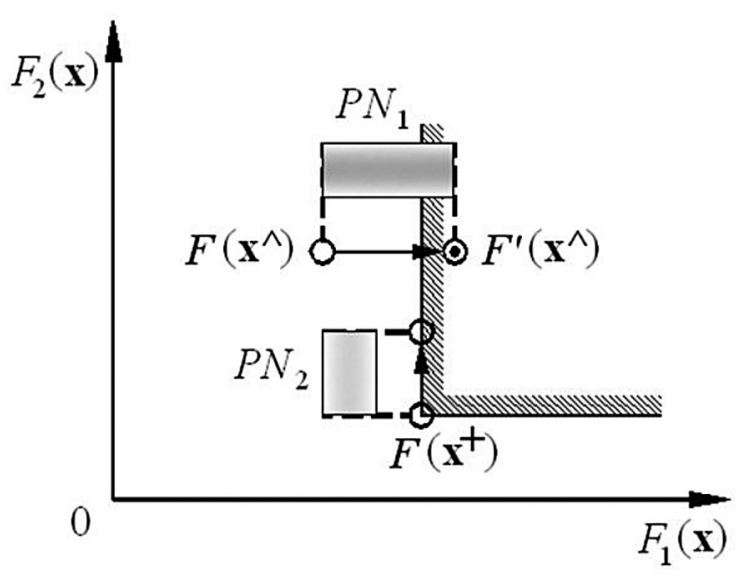

Fig. 8. The task in two-criteria minimisation: $\mathrm{O}-$ solution assessment lying outside the domination cone, - - solution assessment belonging to the domination cone [11]

assessments compared. After this move it can be seen that the assessment of solution $\mathrm{F}^{\prime}\left(\mathrm{x}^{\wedge}\right)$ is inside the domination cone positioned in the assessment of solution $\mathrm{F}(\mathrm{x}+)$, which means that solution $\mathrm{x}^{\wedge}$ is not optimal in the sense of nondifferentiation interval and is eliminated.

The use of the described mechanism allows for the separation of the set of nondominated solutions in to subsets of solutions which are optimal in the sense of nondifferentiation interval. The first generated subset will have the most importance to us. Firstly, it will be less numerous than the original set. Secondly, it will include solutions that are insensitive to small fluctuations of the criteria resulting from the adopted simplifications in the calculation model used. In a smaller subset of solutions it is easier to carry out further analysis that will help us make the final decision. The resulting split will be in part dependent on the value of the $P N$. For this reason, it is worth performing the process of calculation for different values to see what is the sensitivity of individual solutions to changes in the value of the $P N$.

\section{CONCLUSIONS}

The study shows that the subject matter concerning the location of wind farms is an issues till under taken in research work in EU countries. For this purpose, the authors also apply multicriteria optimisation methods, e.g. the ELECTRE TRI method.

Wind energy in Poland has a large potential for the installation of wind farms both onshore and offshore. Modern wind energy, taking into account other energy production technologies, is beneficial both in terms of the future climate and the economy, greatly increasing the chances of regional development.

The concept of using evolutionary algorithms to solve multicriteria technical issues, as this article tries to point out, can be one of many possible solutions related to the selection of the correct location of wind farms.

The authors of the article present their own approach to assist the process of optimal choice of wind farm location, based on the use of the concept of optimality in the sense of nondifferentiation interval.

\section{REFERENCES}

1. Burton J., Hubacek K., Is small beautiful? A multicriteria assessment of small-scale energy technology applications in local governments. Energy Policy 2007.

2. Ehrgott M., Multicriterial optimization. Second Edition. Springer, Berlin 2005.

3. Gumuła S., Wind power (in Polish). AGH, Kraków 2006.

4. Haurant P., Oberti P., Muselli P., Multicriteria selection aiding related to photovoltaic plants on farming fields on Corsica island: A real case study using the ELECTRE outranking framework. Energy Policy 2011.

5. Herva M., Roca E., Review of combined approaches and multi-criteria analysis for corporate environmental evaluation. Journal of Cleaner Production 2013.

6. http://brasil.cel.agh.edu.pl/

7. http://www.baza-oze.pl/

8. http://www.gembc.ca/GIS-Mapping\%20Services. $\mathrm{html}$

9. Lubośny Z., Wind power stations in the electric energy system (in Polish). WNT, Warszawa 2006.

10. Miller B., Using optimisation and multicriteria choice methods in the production process - a case study (in Polish). UP w Kielcach.

11. Montusiewicz J., Division of the set of nondominated solutions by means of the nondifferentiation interval method. [In:] Świć A. (Ed.) The Technological Information Systems, Societas Scientiarum Lublinensis, Lublin 1999.

12. Montusiewicz J., Ranking Pareto optimal solutions in genetic algorithm by using the undifferentiation interval method. [In:] Burczyński T. (Ed.) Evolutionary Methods in Mechanics. Monograph. Kluwer Academic Publishers 2004. 
13. Montusiewicz J., Gryniewicz-Jaworska M., Multicriteria approach in evolutionary optimisation (in Polish). Problemy współczesnej inżynierii. Technologie informacyjne. Wyd. Politechniki Lubelskiej 2014.

14. Nalepa K., Miąskowski W., Pietkiewicz P., Piechocki J., Bogacz P., Guide to small-scale wind power (in Polish). Olsztyn 2011.

15. Sanchez-Lozano J.M., García-Cascales M.S., Lamata M.T., Identification and selection of potential sites for onshore wind farms development in Region of Murcia, Spain. Energy, 2014.

16. Sánchez-Lozano J.M., Teruel-Solano J., Soto-Elvira P., Socorro García-Cascales M., Geographical Information Systems (GIS) and Multi-Criteria Decision Making (MCDM) methods for the evaluation of solar farms locations: Case study in southeastern Spain. Renewable and Sustainable Energy Reviews, 2013.
17. Słowik A., Properties and applications of evolutionary algorithms in optimisation. Methods of Applied Computer Science (in Polish). Kwar. Kom. Inf. PAN O/Gdańsk 2007.

18. Soliński I., Wind energy (in Polish). AGH, Kraków 2010.

19. Theodosiou G., Stylos N., Koroneos C., Integration of the environmental management aspect in the optimisation of the design and planning of energy systems. Journal of Cleaner Production, 2014.

20. The European Wind Energy Association EWEA. Wind in Power European, 2012.

21. Trzaskalik T., Multicriteria assistance in decisionmaking. Review of methods and applications (in Polish). Zeszyty naukowe Pol. Śl., 2014.

22. Wiśniewski G., Wind power - state of the art and development perspectives in Poland (in Polish). Instytut Energii Odnawialnej, Warszawa 2012. 